Devel opment of BNS and Possi bi lity of Perfor mance Based Contracting Usi ng BNS

\begin{tabular}{|l|l|}
\hline 著者 & $\begin{array}{l}\text { Kaneuj i Nakot o, Kawamur a H r oaki, Wat anabe } \\
\text { Ei i chi }\end{array}$ \\
\hline $\begin{array}{l}\text { j our nal or } \\
\text { publ i cat i on t i t l e }\end{array}$ & $\begin{array}{l}\text { Soci et y for Soci al Nanagenent Syst ens I nt er net } \\
\text { J our nal }\end{array}$ \\
\hline vol une & 5 \\
\hline number & 1 \\
\hline year & $2009-03$ \\
\hline URL & ht t p: //hdl . handl e. net /10173/1721 \\
\hline
\end{tabular}




\title{
Development of BMS and Possibility of Performance Based Contracting Using BMS
}

\author{
Makoto KANEUJI*, Hiroaki KAWAMURA*, Eiichi WATANABE*** \\ Kajima Corporation* \\ Aomori Prefectural Government** \\ Kyoto University, Regional Planning Institute of Osaka***
}

\begin{abstract}
There are very many road bridges in Japan, and these bridges are exposed to severe environment and starting to deteriorate. The process of finding the best Bridge Management Plan under the budgetary constraint is complicated, a great amount of effort has been made to develop Bridge Management System (BMS). Most of these BMS are useful in the planning process, but not many are useful in the execution process of bridge management, such as maintenance works, repair works, rehabilitation and replacement works.

The Bridge Management System developed for Aomori Prefectural Government has unique and useful functions such as "Knowledge Base Deterioration Prediction Method”, "Management Scenario Concept” and "Budget Simulation”. After the process of Budget Simulation, the maintenance scenarios of all bridge are determined when the long term budgetary plan is determined. It means that the performance requirements are determined for all bridge components when the mid and long-term bridge management plan are determined. Therefore, it is possible to use data obtained from our BMS and make a "Performance Based Contracting" for the bridge maintenance and preservation works.
\end{abstract}

KEYWORDS: Bridge Management System, Asset Management Contract, Performance Based Contract

\section{INTRODUCTION}

There are over 680 thousand road bridges with span of $2 \mathrm{~m}$ or longer in Japan. Dividing the population of Japan, which is 127,760 thousand in 2005 , by the number of road bridges, we get the number 188. It means that 188 persons have to take care of one bridge.

These bridges are exposed to the rain, snow, wind and also to the traffic load, and deterioration is progressing slowly but steadily. In order to maintain these road bridges properly, we need to identify the deteriorations at their early stage through periodical inspections, and take appropriate actions to stop or delay further deterioration. By estimating the deterioration progress and the time and cost of maintenance actions we need in the future, we can establish an effective and efficient bridge management plan. Since there are so many bridges in different environmental conditions with different deteriorations, the process of establishing the bridge management plan becomes very complicated. Therefore, many attempts have been made to develop Bridge Management System (BMS) to help bridge management planning.

In the construction stage of maintenance works, bridge manager has to take care of even more works, such as decision of performance levels, methods and materials of maintenance works, estimation of cost, contracting, quality control and so on. Considering 
the amount of bridges, the amount of maintenance works and the amount of works to execute all the works associated with the bridge maintenance, it is ideal to establish a new business model suitable for the bridge management.

In this paper, we discuss the possibility of performance based contracting for the bridge management works, and the development of BMS which can be used for the performance based contracting of the bridge maintenance.

\section{PERFORMANCE BASED CONTRACTING}

In the "Performance Based Contracting", the owner indicates the "Performance Requirement" and the contractor proposes to the owner the method and material which satisfies the Performance Requirement with the relevant evidences, and the owner examines the proposal whether it meets the requirement. Since it is difficult for the owner to evaluate whether the proposed method and material satisfy the requirement for a long period, it is usual to establish the method of testing and evaluation during and after the construction. The responsibility to prove that the proposed method and material should satisfy the Performance Requirement belongs to the contractor.

The owner do not have to supervise the quality control of the construction process by itself, but simply evaluate the result of testing and evaluation during and after the construction, and the load of the supervision of the maintenance works becomes much lighter compared to the conventional management.

The contractor has more responsibility to the result of construction, but the room of improvement in the quality control increases because it can propose the method of construction and the material which it has confident in. The load of quality control in the construction does not change because it has to make their best to control the quality anyway.

In the new construction works, the performance requirements are indicated and measured as the performance of the structure at the time of completion of the construction. But, in the maintenance works, most of the maintenance actions are carried out to the deteriorated structures and evaluation of the maintenance works should be focused on the durability of the maintenance actions. Therefore, the performance requirement should be indicated as the combination of the performance level to take maintenance action and its durability.

The Figure- 1 shows the determination of performance requirement. It is insufficient to indicate the performance requirement only by the management level to take maintenance action, because the duration of the effect of maintenance actions may vary depending on the maintenance method. The method has the high performance recovery and the longest duration, the method has the high performance recovery but shorter duration, and the method has the low performance recovery and shorter duration of the maintenance effect. Therefore, the performance requirement should be indicated as the combination of management level to take maintenance action, performance recovery and the expected duration of its effect.

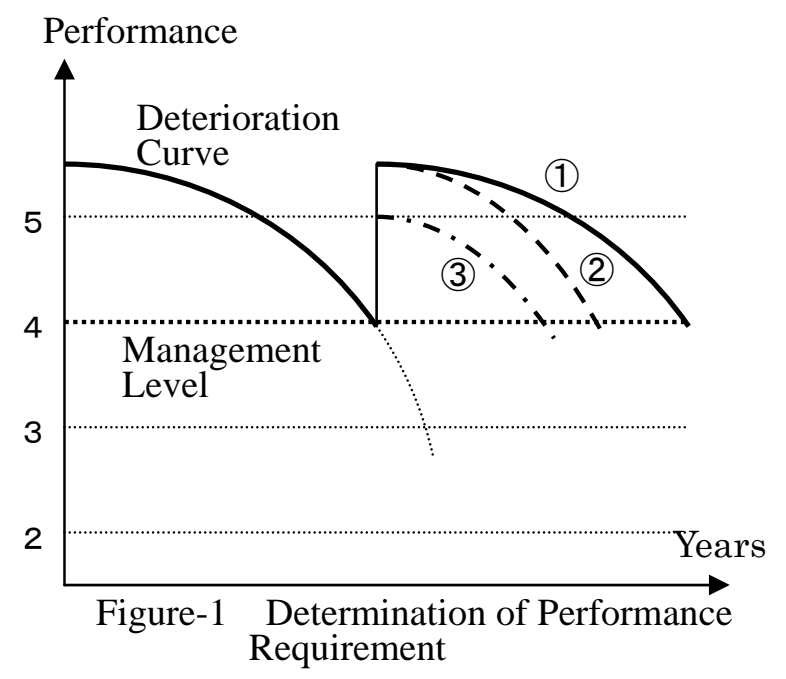


Figure2 shows an example of determination of Performance Requirement for the concrete structure in the coastal area suffering from Chloride Ion Intrusion. The vertical axis indicates the Condition States used as an index representing Performance, and the horizontal axis indicates years.

The first management criterion is the Management Level where the Chloride ion concentration is below the threshold and Surface Protection can be effectively applied (1) in the Figure 1). Once the Chloride ion concentration exceeds the threshold, the reinforcement bars will corrode and the Surface Protection is not effective anymore.

The second management criterion is the Management Level where the amount of corrosion of reinforcing steel bars is minimal and Cathodic Protection can be applied effectively (2) in the Figure 2).

Once the amount of corrosion increases and the concrete structure needs to have some form of structural reinforcement, the rehabilitation with Cathodic Protection and structural reinforcement becomes inefficient in terms of cost analysis. It is better to replace the structure in such a case (3) in the Figure3).

In the development of BMS, it is necessary to establish the abovementioned Performance Requirements with the management levels and the maintenance measures.

\section{Condition State}

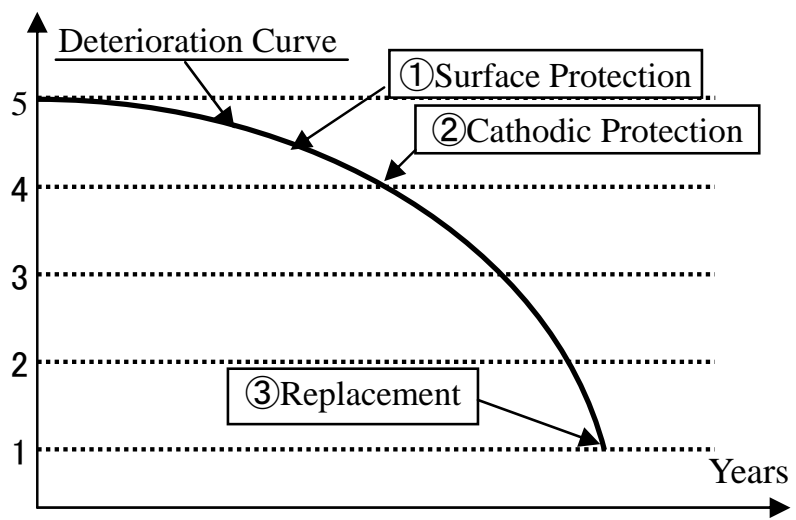

Figure 2 Management Level of Concrete Structure Suffering from Chloride Ion Intrusion

\section{OUTLINE OF BMS}

We have developed the Bridge Management System (BMS) for the purpose of Life Cycle Cost Reduction under a given budget constraint. In order to achieve the LCC reduction, we have established the various management levels at which we take maintenance actions, and select a plan which has the smallest LCC.

The main features of our BMS are follows;

1) Condition state evaluation standards have been established for different bridge components and for different deterioration phenomena.

2) Condition state evaluation standards are related to the deterioration process

3) Condition state evaluation standards are used for the definition of performance requirement

4) Condition state evaluation standards are used as index for the deterioration curve

5) Condition state evaluation standards are related to the maintenance measures

6) A concept of Management Scenario has been established as the package of performance requirement for different bridge components and different deterioration phenomena

The outline of our BMS is as shown in Figure-2.

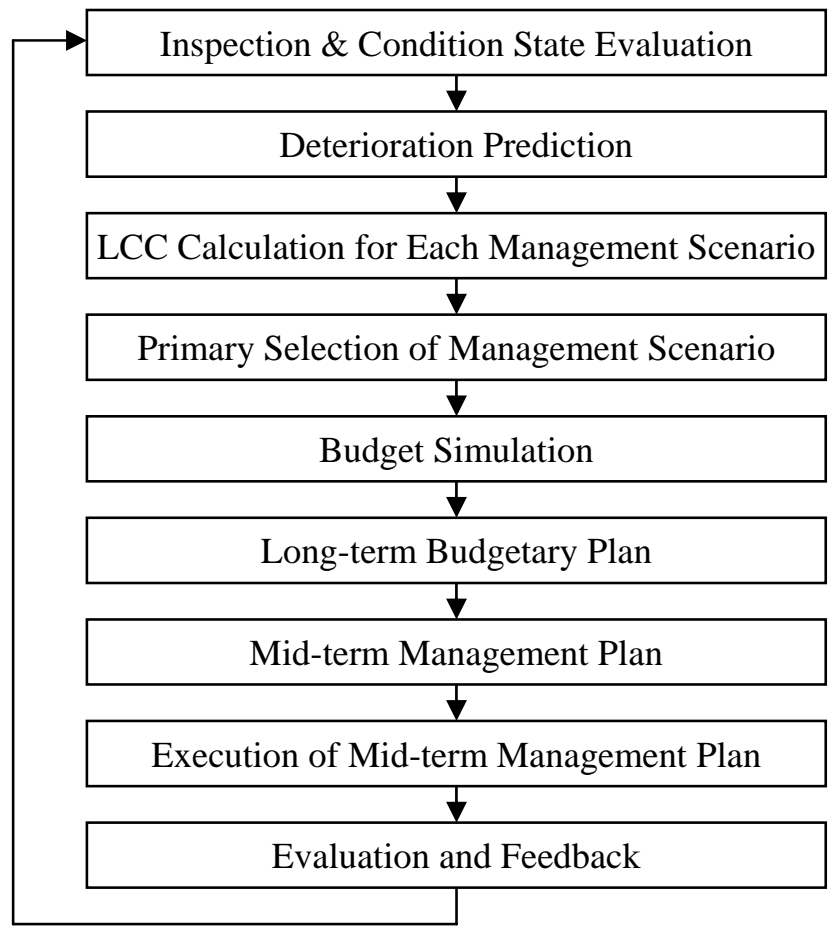

Figure-2 Outline of Bridge Management System 
3.1 Inspection and Condition State Evaluation Standard

The performances required to the structures are Safety, Usability, Third Party Safety (Prevention of damage to a third party), Aesthetics and their Durability. It is ideal to evaluate these performances separately for each bridge elements. But in the process of bridge management, it is too much time consuming to evaluate these performances separately for every bridge component. Therefore, it is usual to use "Condition State", or "Health Condition State" as an index to evaluate performances.

The Condition State Evaluation Standard we have established has characteristics as follows.

(a) Definition common to different elements

The Condition States Evaluation Standard should be defined individually for different elements, materials or deterioration phenomena, but it is desirable for each Condition State to have common meaning from the management point of view (Table-1).

(b) Relation to the Deterioration Curve

The Condition State Evaluation Standard are related to the deterioration curve.

(c) Relation to the Maintenance Measures

The Condition State Evaluation Standard are related to the maintenance measures. Therefore, it is possible to indicate the maintenance measures at each performance level.
Table-1 Definition of Condition State Evaluation Standard

\begin{tabular}{cl}
\hline $\begin{array}{c}\text { Condition } \\
\text { State }\end{array}$ & $\begin{array}{l}\text { Definition of Condition State Evaluation } \\
\text { Standard Common to All Deteriorations }\end{array}$ \\
\hline 5 & $\begin{array}{l}\text { The deterioration has not started yet, or has } \\
\text { not revealed on surface even if it has } \\
\text { started under the surface. }\end{array}$ \\
\hline 4 & $\begin{array}{l}\text { The deterioration has started and continues } \\
\text { to progress. The deterioration may be } \\
\text { revealed on the surface. Even if the } \\
\text { deterioration is not revealed on the surface, } \\
\text { it can be detected by non-destructive } \\
\text { methods }\end{array}$ \\
\hline 3 & $\begin{array}{l}\text { The progress of deteriorations starts to } \\
\text { accelerate at this stage. The structural safety } \\
\text { degrades, but the required structural strength } \\
\text { is supposed to be secured. }\end{array}$ \\
\hline 2 & $\begin{array}{l}\text { The deterioration continues to progress. } \\
\text { The structural strength considerably } \\
\text { degrades at this condition state. Even though } \\
\text { the required strength is barely secured, } \\
\text { prompt maintenance actions are needed }\end{array}$ \\
\hline 1 & $\begin{array}{l}\text { The deterioration proceeded quite badly to a } \\
\text { point where the required performance of the } \\
\text { structure is not secured. The structural safety } \\
\text { is sometimes in danger. In such cases, } \\
\text { emergency measures are necessary }\end{array}$ \\
\hline
\end{tabular}

\subsection{Deterioration Prediction}

There are several approaches to establish the deterioration curves.

The first approach is the theoretical and experimental approach. This is based on the theoretical analysis of deterioration phenomena or the experimental data. The process of analyzing the deterioration phenomena is essential and very useful, but the deterioration process in the field is affected by many factors such as the local environmental conditions or the characteristics of the material, and we do not have sufficient data to analyze every deterioration process.

The second approach is a statistical approach based on the analysis of inspection data. Since the inspection data are supposed to reflect many conditions which have affected the speed of deterioration, it is desirable to establish deterioration curves based on the existing inspection data. But, the periodical inspection is intended to find severe damages or deteriorations that need maintenance 
actions and are not related deterioration process. Therefore, it is difficult to get information useful for the deterioration prediction from existing inspection data.

Therefore, we have established a new approach and named it as "Knowledge Base Deterioration Prediction System". The concept of this approach is to establish Deterioration Model Curves based on existing knowledge such as experts' knowledge, theoretical and experimental findings and existing field data, and modify Deterioration Model Curves by reflecting inspection data.

(1) Establish Deterioration Model Curves based on

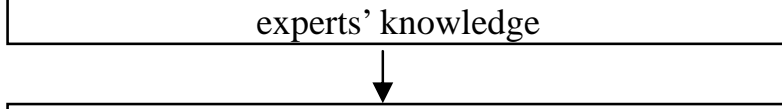

(2) Modify Deterioration Model Curves by reflecting inspection data

(3) Customize Deterioration Model Curves based on accumulated inspection data

Figure-3 Knowledge Base Deterioration Prediction System

The modification process of Deterioration Model Curve is shown in Figure-4. The Deterioration Model Curve is modified as to go through the inspection data for every element. By this modification, the condition state of that element in the future will be much closer to its real deterioration.

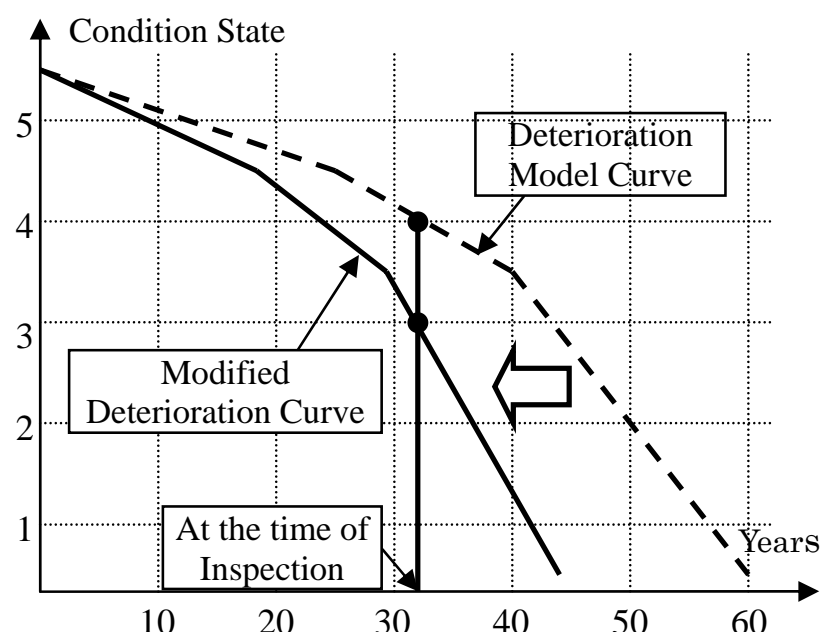

Figure- 4 Modification of the Deterioration Curve by reflecting inspection data

\subsection{LCC Calculation}

Once the deterioration curve is obtained, and the management level is indicated, the remaining information necessary to calculate LCC are the information on the maintenance measures and the deterioration curve after the maintenance actions.

Information necessary to calculate LCC are as follows;

1) Condition state obtained by the inspection

2) Deterioration curve

3) Management level to take maintenance action

4) Maintenance measure

5) Cost of maintenance action

6) Recovery of condition state after the maintenance action

7) Deterioration curve after the maintenance action

Condition State

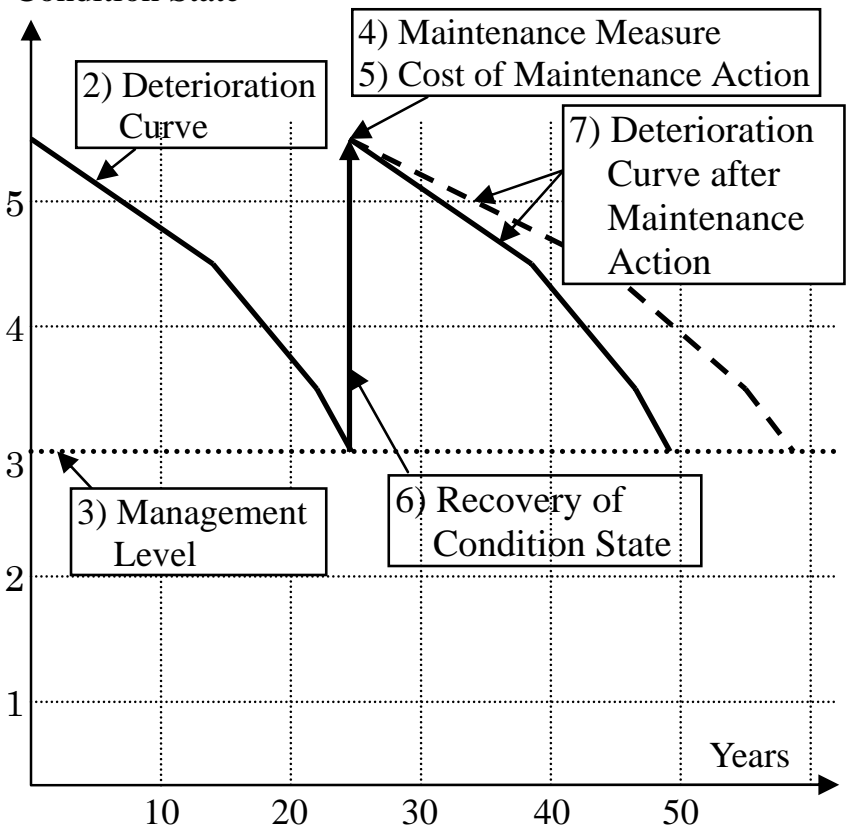

Figure- 5 Information necessary for LCC calculation

\subsection{Management Scenario}

In order to execute deterioration prediction and LCC calculation, we need to indicate the management level to execute maintenance measures. 
It is possible to have many different combinations of management levels and maintenance measures for each bridge, but it is more practical to limit the number of combinations from the management point of view. Therefore, we have established a concept of Management Scenario which has a combination of maintenance measures to be executed at designated management levels.

\subsubsection{Establishment of Management Scenarios}

We have established four different management levels for each bridge component and deterioration phenomena as shown in Figure-6.

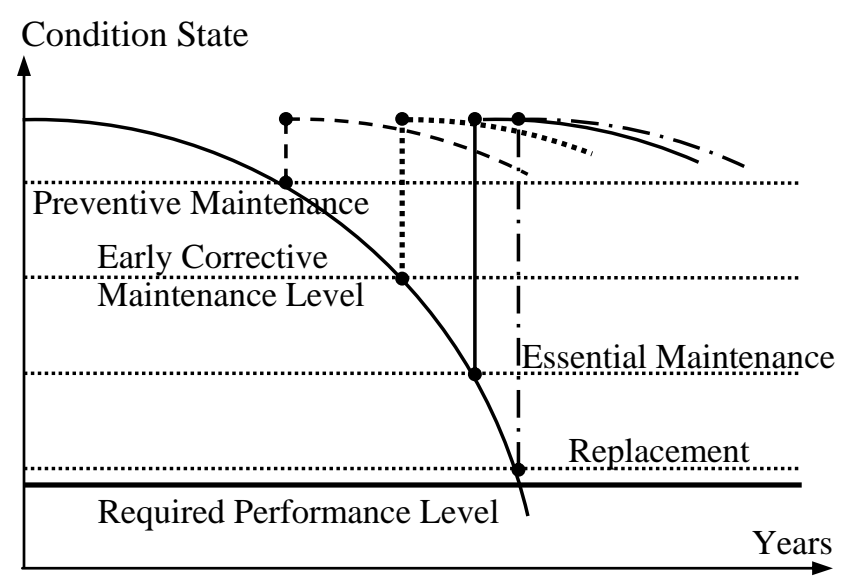

Figure-6 Different management levels

At the same time, we have established four main Management Scenarios as shown in Table2.

Table-2 Classification of Management Scenarios

\begin{tabular}{c|l}
\hline $\begin{array}{c}\text { Management } \\
\text { Scenario }\end{array}$ & \multicolumn{1}{c}{\begin{tabular}{c}
\multicolumn{1}{c}{ Specification of } \\
Management Scenario
\end{tabular}} \\
\hline Maintenance & $\begin{array}{l}\text { Highest management level. } \\
\text { Apply preventive maintenance to } \\
\text { avoid essential maintenance or } \\
\text { replacement that will create traffic } \\
\text { restriction. }\end{array}$ \\
\hline $\begin{array}{c}\text { (B)Early } \\
\text { Corrective } \\
\text { Maintenance }\end{array}$ & $\begin{array}{l}\text { Second highest management level. } \\
\text { Take appropriate maintenance } \\
\text { actions as soon as any sign of } \\
\text { deterioration is observed. }\end{array}$ \\
\hline Maintenance & $\begin{array}{l}\text { Second lowest management level. } \\
\text { Delay maintenance actions until the } \\
\text { deterioration proceeds to the } \\
\text { designated condition state } \\
\text { appropriate for the maintenance } \\
\text { measures. }\end{array}$ \\
\hline (R)Replacement & $\begin{array}{l}\text { Maintain bridges to secure the } \\
\text { safety until the time of replacement. }\end{array}$ \\
\hline
\end{tabular}

The first three management scenarios, Preventive Maintenance Scenario, Early Corrective Maintenance Scenario and Essential Maintenance Scenario, are referred to as Life Prolongation Scenarios, and each of them has two subdivisions.

It is ideal to apply best management scenarios to all bridges, but in most cases it is not possible because of budgetary constraint. Therefore, it is better to have alternative management scenario for such an occasion.

\subsubsection{Primary Selection of Management Scenarios}

In our BMS, a function called Budget Simulation is facilitated to find out the best combination of management scenarios for all bridges to obtain a bridge management plan which satisfies the given budgetary constraint. Therefore, the bridge manager has to select the best management scenario and acceptable alternatives for each bridge before getting into the budget simulation process. This process is called Primary Selection of Management Scenario.

The first step of the Primary Selection of Management Scenarios is the selection of the bridges to apply Replacement Scenario. Severely damaged bridges are the typical example for Replacement Scenario, when the LCC of the replacement scenario is less expensive than the repetition of expensive rehabilitations. Also, aged bridge with insufficient strength or insufficient function is another example.

The second step is to select bridges to apply only Preventive Maintenance Scenario. The bridges which have very important role in the road network are usually chosen.

The third step is to select appropriate scenarios from preventive maintenance, early corrective maintenance or essential maintenance scenarios for the rest of the bridges, taking various factors, such as bridge condition states, environmental conditions and the role of the bridges in the road network, into 
account.

\subsection{Budget Simulation}

In the process of establishing a long-term budgetary plan, it is inevitable to change some of the individual management scenario due to the budgetary constraint.

When there is more maintenance works than the available budget for a certain period, the most common procedure is to choose maintenance works to allocate available budget based on a certain priority assessment, and postpone the rest of maintenance works in the plan. When those maintenance works are postponed for a long period, the original plan may not be applicable because deterioration proceeds in time.

In our BMS, we developed a new method of Budget Simulation to make a feasible management plan for all bridges under a certain budgetary constraint. The procedure is as follows;

(1) When there is more maintenance works than the available budget for a certain period, find a bridge which has an alternative plan which do not have maintenance work planned within that period, and re-calculate LCC and compare with the available budget.

(2) If the re-calculated LCC is still larger than the available budget, select the second bridge to change its maintenance plan. And continue this procedure until you get a management plan for all bridges which satisfy the budgetary constraint.

Figure 6 shows the result of Budget Simulation applied for the 742 bridges of Aomori Prefecture in 2005.

Case1 is the budgetary plan for the combination of Management Scenario with the smallest LCC for each bridge. Since there is a tendency that
Preventive Maintenance Scenario gives the smaller LCC, but requires some maintenance actions in the early stage, there is a great amount of maintenance works needed at the beginning.

Case2 is the budgetary plan with 2.2 billion yen for the first five years. The total LCC for 50 years is 90.2 billion yen which is 11.5 billion yen larger than Case1.

Case3 is the final solution which gives 1.85 billion yen lower budget than Case1 for the first five years, with 2.0 billion yen larger for the 50 years.

The bridge manager can show several alternatives in the process of budgetary planning very easily by using Budget Simulation.

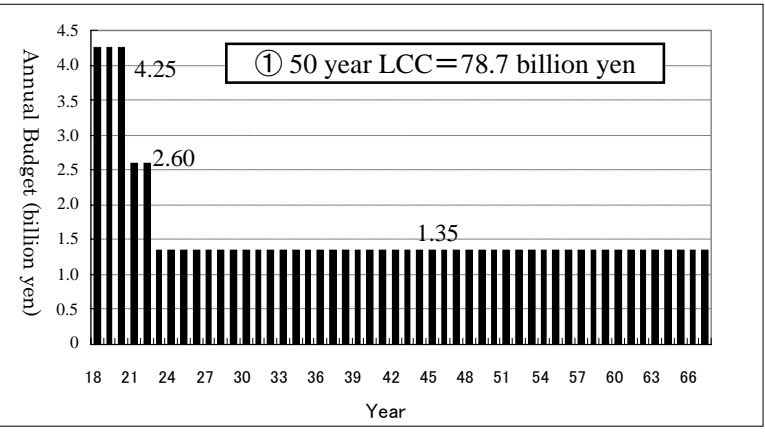

Case1 Scenarios with Smallest LCC

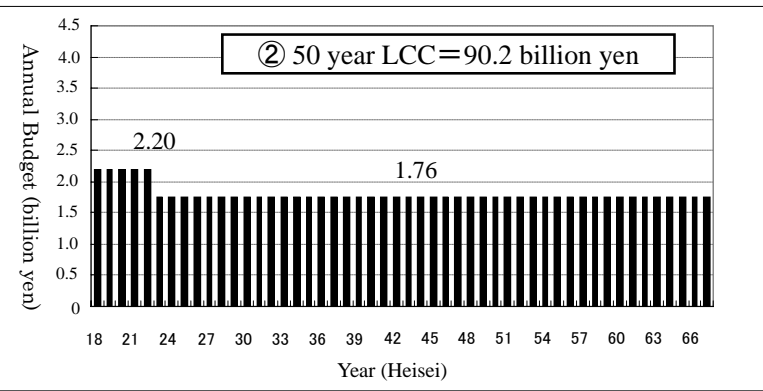

Case2 First 5 Years with 2.2billion yen

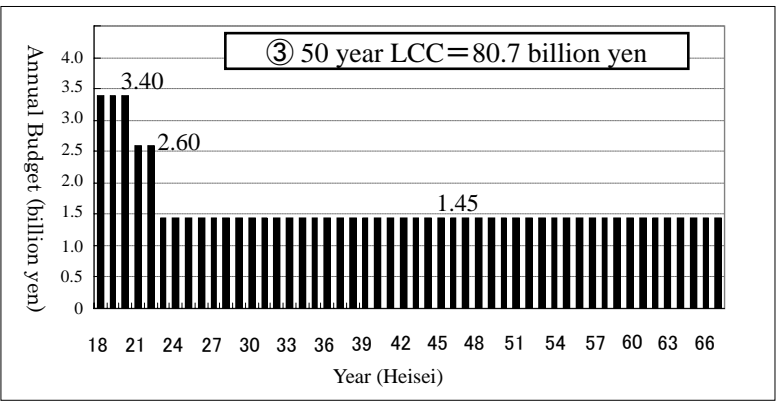

Case3 Final Budget Plan

Figure6 Result of Budget Simulation 


\subsection{Mid-term Bridge Management Plan}

Once the long-term budgetary plan is established with a combination of Management Scenarios for all bridges, the Five-year Bridge Management Plan can be made very easily with the maintenance works listed in an order of urgency as shown in Table 2.

\section{CONCLUSION}

In our BMS, when the long-term budgetary plan is finalized, Management Scenarios are determined for all bridges. Since performance requirements of all bridge components are defined for each Management Scenario, it is possible to indicate performance requirement for every bridge component. Therefore, there is a possibility to make a Performance Based Contracting by showing the Five-year Bridge Management Plan obtained by our BMS to the contractor.

The Performance Based Contracting has been widely adopted by many States' Department of Transportation in the United States for highway maintenance works, because it is effective, efficient and best suited for the maintenance work. The Performance Based Contracting itself is not popular in Japan yet, but it will soon be recognized as the best suited contracting method for the maintenance works as the amount of maintenance work increases in the near future.

\section{ACKNOWLEGEMENTS}

We do express great appreciation to the members of Aomori Bridge Management Consortium for their effort in the course of development of the Bridge Management System.

\section{REFERENCES}

Kaneuji, M., Asari, H., Takahashi, Y., Ohtani, H., Ukon, H. \& Kobayashi, K. 2006: Development of BMS for a large number of bridges, in: Bridge Maintenance, Safety, Management, Life-Cycle Performance and Cost, in Cruz, Frangopol \& Neves (eds), Proc. of the third IABMAS conference, Porto

Yamamoto, N., Asari, H., Ishiawa, T., Kaneuji, M. \& Watanabe, E. 2006: Implementation of bridge management system in Aomori Prefectural Government, Japan, in: Bridge Maintenance, Safety, Management, Life-Cycle Performance and Cost, in Cruz, Frangopol \& Neves (eds), Proc. of the third IABMAS conference, Porto

Matsumura, E., Senoh, Y., Sato, M., Miyahara, Y., Kaneuji, M. \& Sakano, M. 2006: Condition evaluation standards and deterioration prediction for BMS, in: Bridge Maintenance, Safety, Management, Life-Cycle Performance and Cost, in Cruz, Frangopol \& Neves (eds), Proc. of the third IABMAS conference, Porto

Kigure, T., Ishizawa, T., Hosoi, Y., Fujii, H., Iwai, M. \& Kaneuji, M. 2006: Development of the inspection support system for bridge asset management, in: Bridge Maintenance, Safety, Management, Life-Cycle Performance and Cost, in Cruz, Frangopol \& Neves (eds), Proc. of the third IABMAS conference, Porto 